\title{
Evaluating Changes in the Prevalence of the Autism Spectrum Disorders (ASDs)
}

\author{
Catherine E. Rice, $\mathrm{PhD},{ }^{1}$ \\ Michael Rosanoff, MPH, ${ }^{2}$ \\ Geraldine Dawson, $\mathrm{PhD}, 2,3$ \\ Maureen S. Durkin, PhD, DrPH, ${ }^{4}$ \\ Lisa A. Croen, $\mathrm{PhD},{ }^{5}$ \\ Alison Singer, MBA, ${ }^{6}$ \\ Marshalyn Yeargin-Allsopp, MD $^{1}$
}

\begin{abstract}
Autism spectrum disorders (ASDs) are estimated to occur among about one percent of children in the United States. This estimate is in line with estimates from other industrialized countries. However, the identified prevalence of ASDs has increased significantly in a short time period based on data from multiple studies including the U.S. Centers for Disease Control and Prevention's (CDC) Autism and Developmental Disabilities Monitoring (ADDM) Network. Whether increases in ASD prevalence are partly attributable to a true increase in the risk of developing ASD or solely to changes in community awareness and identification patterns is not known. It is clear that more children are identified with an ASD now than in the past and the impact on individuals, families, and communities is significant. However, disentangling the many potential reasons for ASD prevalence increases has been challenging. Understanding the relative contribution of multiple factors such as variation in study methods, changes in diagnostic and community identification,
\end{abstract}

\footnotetext{
${ }^{1}$ National Center on Birth Defects and Developmental Disabilities, Centers for Disease Control and Prevention, USA.

${ }^{2}$ Autism Speaks, USA.

${ }^{3}$ University of North Carolina at Chapel Hill, USA.

${ }^{4}$ University of Wisconsin-Madison, USA.

${ }^{5}$ Kaiser Permanente ${ }^{4}$ Autism Research Program, USA.

${ }^{6}$ Autism Science Foundation, USA.
}

Corresponding Author Contact Infromation: Catherine E. Rice at crice@cdc.gov and www.cdc.gov/autism; National Center on Birth Defects and Developmental Disabilities, Centers for Disease Control and Prevention, 1600 Clifton Road, MS E-86, Atlanta, Georgia, 30333, USA.

Disclaimer: The findings and conclusions in this report are those of the authors and do not necessarily represent the official position of the Centers for Disease Control and Prevention (CDC). 
and potential changes in risk factors is an important priority for the ADDM Network and for CDC. This article summarizes the discussion from a workshop that was co-sponsored by CDC and Autism Speaks as a forum for sharing knowledge and opinions of a diverse range of stakeholders about changes in ASD prevalence. Panelists discussed recommendations for building on existing infrastructure and developing new initiatives to better understand ASD trends. The information, research, and opinions shared during this workshop add to the knowledge base about ASD prevalence in an effort to stimulate further work to understand the multiple reasons behind increasing ASD prevalence.

Key Words: Autism, autism spectrum disorders, ASD, prevalence, occurrence

Suggested Citation: Rice CE, Rosanoff M, Dawson G, Durkin MS, PhD, Croen LA, PhD, Singer A, Yeargin-Allsopp M. Evaluating changes in the prevalence of the autism spectrum disorders (ASDs). Public Health Reviews. 2012;34: epub ahead of print.

\section{INTRODUCTION}

Autism spectrum disorders (ASDs) are neurodevelopmental conditions characterized by impairments in social interactions and communication and restricted, repetitive and stereotyped patterns of behavior that typically emerge in the first few years of life. ${ }^{1}$ ASDs typically refer to the three subtypes of pervasive developmental disorders of autistic disorder, Asperger disorder, and pervasive developmental disorder not otherwise specified. ${ }^{2}$ In addition to the core areas of impairment in social, communication, and behavioral domains, people with ASDs frequently have co-occurring conditions, such as intellectual disability, seizures, psychiatric co-morbidities (e.g., attention deficit/hyperactivity disorder (ADHD), anxiety), gastrointestinal conditions, and sleep disturbance. Typically, autism is manifest by the time a child is three years of age and is life-long., ${ }^{2,3}$ However, there is variability in the pattern and severity of symptoms and in the timing of diagnosis. ${ }^{4}$

Although autism was once seen as a single disorder, incorrectly attributed to a failure of parenting, autism is now seen as a complex neurodevelopmental disorder that occurs with a range or spectrum of presentations. ${ }^{3}$ Many studies have consistently shown higher concordance between monozygotic as compared to dizygotic twins, suggesting there is a strong genetic component associated with ASDs. ${ }^{5,6}$ ASDs have been associated with multiple genetic variations including rare gene mutations, chromosomal deletions or duplications, and methylation differences. It is estimated that a specific genetic mutation can be identified in about ten percent to 15 percent of people with an ASD with more identified as technology improves. ${ }^{5}$ These mutations tend to be implicated in other 
conditions (e.g., ADHD, intellectual disability). Although multiple, complex genetic and environmental interactions are likely, there is very limited information on what predisposes a child to have an ASD, what might increase risk, and which risks lead to the development of an ASD. . $^{5,-9}$

In the past autism was thought to be a rare condition, affecting about one in 2,000 individuals. ${ }^{10,11}$ Beginning in the mid-1990s, concerns arose about increases in the numbers of individuals with autism identified in service systems in the United States. ${ }^{12,13}$ Population-based studies in the US that were initiated in the $1990 \mathrm{~s}^{14,15}$ found the identified prevalence of ASDs had increased significantly in a short time period. Multiple other studies confirmed this., ${ }^{4,12,16-18}$ Current estimates are that ASDs occur in about one percent of children., ${ }^{4,10,19-24}$ Prevalence estimates are important for planning policy and service needs and identifying potential risk factors for ASD. ${ }^{25}$ Concerns about increases in ASD prevalence have fueled local, state, national, and international action in terms of advocacy, policy-development, research, and service development. However, individuals and families continue to have many needs associated with ASDs across their lifespan.

There are several potential explanations for an increase in the observed prevalence of ASDs including better analytic tools, better identification and screening methods, changes in diagnostic criteria, increased awareness among parents and clinicians, and changes in the availability of services. However, prevalence reports often also include the statement "a true increase in prevalence cannot be ruled out." ${ }^{11,26}$ Some studies have examined how much of the increase is accounted for by specific risk factors, such as increasing parental age. ${ }^{17}$ However, a full explanation must consider multiple factors that are not independent of each other.

This article summarizes the discussion from a workshop that was co-sponsored by CDC and Autism Speaks. ${ }^{8}$ The purpose of the workshop was to bring together experts in prevalence and surveillance of ASDs and other conditions as well as stakeholders to: summarize what is known about ASD prevalence; learn from efforts to document prevalence changes among other conditions; and improve the specificity in quantifying and qualifying the multiple factors that might be influencing trends in ASD prevalence. Although the focus of the workshop was on US-based data and trends, similar patterns are seen in other developed countries. ${ }^{19-23}$ Panelists discussed points for building on existing infrastructure and for developing new initiatives to better understand ASD trends. The information, research, and opinions shared during this workshop add to the knowledge base about ASD prevalence in an effort to stimulate further work to understand the multiple reasons behind increasing ASD prevalence (Table 1). ${ }^{8}$ 


\section{Table 1}

Categories of Factors that May Influence ASD Prevalence Trends

$\begin{array}{cl}\begin{array}{c}\text { 1. Intrinsic } \\ \text { Identification }\end{array} & \begin{array}{l}\text { Internal methodology or measurement factors involved in documenting } \\ \text { ASD prevalence trends (e.g., differences in study methods may lead to } \\ \text { different individuals being counted or not counted as having an ASD such } \\ \text { as using a registry of children identified with an ASD or active screening). }\end{array} \\ \begin{array}{cl}\text { 2. Extrinsic } \\ \text { Identification }\end{array} & \begin{array}{l}\text { External classification and awareness factors involved in identifying people } \\ \text { with ASDs in the population (e.g., changes in diagnostic criteria or access } \\ \text { to services based on an ASD label may influence who is identified for ASD } \\ \text { prevalence studies). }\end{array} \\ \text { 3. Risk } & \begin{array}{l}\text { Possible etiologic or true change in ASD symptoms among the population } \\ \text { in relation to single or combined genetic, biologic, or environmental } \\ \text { factors, or a combination thereof (e.g., specific biologic vulnerabilities or } \\ \text { exposures in the environment that increase the risk of developing an ASD). }\end{array} \\ & \end{array}$

\section{ASD PREVALENCE}

There are three main measures of occurrence of a condition: prevalence (the number of cases divided by the number of people in the population at a given time), incidence (the number of new cases among a given population in a defined time divided by the amount of person-time observed during the same period), and cumulative incidence (the number of new cases identified in an extended time period [e.g., from birth] divided by the size of the population without the disorder at the start of the time period). A condition where the diagnosis tends to be stable (e.g., low mortality rate and stable diagnosis) can result in prevalence and cumulative incidence measures that will be virtually identical over a defined time or age period. ${ }^{8}$ All measures are affected by changes in identification patterns and diagnostic practices. Prevalence studies can provide observations that might need further causal examination. For example, prevalence studies have shown that there are about four to five boys for every one girl with an ASD. ${ }^{9}$ However, basic studies of individuals with an ASD are necessary to explain the biologic mechanism that results in boys being affected more than girls. In addition, other types of epidemiologic studies, such as case-control designs may help us understand ASD risk factors.

\section{Service-Based Data}

Starting in the 1990s, the U.S. Department of Education's Office of Special Education and the California Department of Developmental Services (CA 
DDS) documented increases in the need for autism services. ${ }^{12,13}$ There is an annual count of children enrolled in special education services as an accountability measure required by the 1990 Individuals with Disabilities Education Act (IDEA) based on select eligibility categories for each state. ${ }^{27}$ Autism was not initially a category within the child count, but states were required to report autism beginning in 1991. The number of children classified as having autism and receiving special education services has increased since the early 1990s. ${ }^{13}$ However, the total numbers are still fewer than would be expected given current prevalence estimates. ${ }^{4} \mathrm{~A}$ special education label does not always match the medical diagnosis that a child may have to describe developmental challenges, and enrollment counts might not have provided a true prevalence of ASD as the special education system never was intended to serve a public health surveillance role. These data are more useful in understanding variation in state-level special education criteria and services and examining barriers to timely identification. ${ }^{8}$

The CA DDS administrative data have been used to evaluate trends among children receiving services for ASD, mainly those meeting criteria for autistic disorder. ${ }^{12}$ The CA DDS tracks service provision for five conditions (autism, epilepsy, cerebral palsy, intellectual disability, and intellectual disability-related conditions) across 21 regional centers. Data collection is passive in that a child must be brought to a CA DDS center and a parent or guardian must request an evaluation to determine if they meet eligibility criteria. Comparing births in 1990 with those in 2001 (followed to age ten), the cumulative incidence of autism in the CA DDS rose 600 percent. There was substantial variability among the centers. About 200 percent of this increase could be explained by trends toward younger age at diagnosis, inclusion of more mild cases, changes in diagnostic criteria, and older ages of mothers. ${ }^{8,17,27-29}$ It has been estimated that about 50 percent of administrative autism prevalence increases in the CA DDS data could be explained by several identification factors, such as diagnostic changes in the use of intellectual disability (mental retardation), earlier age of diagnosis, social influence of people sharing information on ASDs; and potential risk indicators, such as closely-spaced pregnancies and increasing parental age. ${ }^{8,18,30-32}$ A recent study indicates that these trends are due to factors that have changed in a linear fashion, aggregate among birth cohorts, and disproportionately impact more mild forms of ASD ${ }^{33}$ At this point, changes over time related to diagnostic criteria, methods for ascertainment and some risk factors appear to explain part, but not all, of the increase in autism cumulative incidence in the CA DDS system. However, more complex methods are needed to evaluate the overlapping relationships between the different and yet unstudied factors as they relate to ASD prevalence changes. ${ }^{8}$ 


\section{Population-Based Data}

Methods for determining prevalence that rely on service systems, registries, and surveys of people already diagnosed under-ascertain individuals with autism. ${ }^{4,10}$ Epidemiologic studies that systematically screen the population, which may result in identification of individuals who were not previously classified as having an ASD, generally result in higher and more complete prevalence estimates. Most epidemiologic studies of ASDs have been conducted in Europe, North America and areas of Asia; there is limited information on the occurrence and characteristics of ASDs in other areas of the world. ${ }^{10}$ Since the first epidemiologic study of autism prevalence in the 1960s, many studies spanning changing diagnostic criteria have estimated the prevalence of ASDs.

From the 1940s until the 1980s autism primarily referred to more severely affected individuals with autistic disorder and was thought to be rare, affecting approximately one in every $2,000(0.05 \%)$ children. ${ }^{10,11,26}$ Several studies using the current International Classification of Diseases $(I C D-10)$ and the American Psychiatric Association Diagnostic and Statistical Manual of Mental Disorders (DSM-IV) have been conducted in industrialized countries identifying not only autism, but the wider spectrum indicating a best estimate of combined ASD prevalence at six or seven per $1,000(0.6 \%$ or $0.7 \%)$ children. ${ }^{11}$ These estimates are more than ten times higher than estimates using earlier criteria. However, some of the most recent population-based studies have documented even higher ASD prevalence estimates of more than one percent, ${ }^{4,16,19-23}$ and over two percent among children in some areas of Asia, Europe, and North America., ${ }^{4,34,35}$

Prevalence studies that involve direct screening of a population generally report higher ASD prevalence estimates than those based on administrative data or service records. ${ }^{20,34}$ The validity of population-based screening can, however, be compromised by low response rates and possible false screening results. Screening can also focus more narrowly on groups at-risk who have been identified for some type of developmental concern in order to maximize resources and minimize the number of children referred for diagnostic assessments. The CDC's ADDM Network, a multi-site study using record review, found that 21-23 percent of the children identified with ASDs did not have a previous ASD classification documented in their records., ${ }^{416}$ The most recent ADDM Network estimates indicated that, on average, one in 88 children (range from 1 in 47 to 1 in 210) were identified with an ASD and had increased 78 percent over a six-year period from 2002 to $2008 .{ }^{4}$ The overall trend in ASD prevalence showed consistent increases, but variation existed among sites and among subgroups. The increase in observed ASD 
prevalence at ADDM Network sites could be partly explained by identification factors such as better information available in records, a more stable population at some sites, and improved identification of specific subgroups such as Hispanic children and children without cognitive impairment; however, these identification factors did not explain the total increase in prevalence, ${ }^{4,16,36}$

Data from the ADDM Network can be used to examine some of the potential factors impacting ASD prevalence. Although it has been stated that the changes in diagnostic criteria that occurred in the DSM in 1980 (DSM III), 1987 (DSM III-R), and 1994 (DSM-IV and minor changes for $D S M-I V-T R$ in 2000) have affected reported ASD prevalence, no known studies have quantified this effect directly. ${ }^{10} \mathrm{~A}$ preliminary analysis recoding the ADDM Network data based on the three diagnostic standards, indicated similar autism and ASD prevalence using DSM III and III-R standards, but estimates increased significantly using $D S M-I V-T R$ standards. A portion of the prevalence increase over time might have been attributed to differences in the definitions of ASD used for identification of ASDs by community professionals and service systems. ${ }^{8}$

Other analyses using ADDM Network data have examined a range of factors such as parental age, age of autism identification, perinatal risk factors, exposures, and socioeconomic status (SES) among others. ${ }^{37-41} \mathrm{~A}$ relatively consistent finding in recent epidemiologic studies is a positive association between advanced parental age at conception and risk of ASD in offspring. ${ }^{17,42}$ Despite the association between ASD and parental age and the increasing trend in mean parental age in recent decades, only a very small (less than 0.5\%) proportion of the recent increase in ASD prevalence can be attributed to the increasing age of parents at conception. ${ }^{8}$ There is some evidence that indicates that ASD is positively associated with higher SES. In this way, it differs from many other developmental disabilities, which tend to be more common in socioeconomically disadvantaged populations. ${ }^{9}$ Examining SES among ADDM Network data, it was found that the ASD prevalence increased with increasing SES in a stepwise manner, suggesting either increased risk with increasing SES or, perhaps more likely, identification disparities. ${ }^{39}$ ASD prevalence estimates likely underestimate prevalence in lower SES groups. This implies that we are still underestimating ASD prevalence and can expect some increases if disparity gaps are closed over time. Further examination of characteristics across cohorts and subgroups will be important in understanding potential identification and risk factors contributing to ASD prevalence increases. ${ }^{8}$ 


\section{Lessons from Other Conditions and Analytic Methods}

There are other complex conditions, such as cancer, Parkinson's disease, asthma, and schizophrenia, where evaluating prevalence changes and understanding biologic and environmental contributions has been a challenge. They provide some examples of how analytic models may be used to understand condition trends. ${ }^{8}$

Changes in cancer trends can be seen from changes in: 1) diagnosis or detection (e.g., screening and biopsy techniques); classification (e.g., staging and grading techniques); and 3) exposures (e.g., smoking, diet, and obesity) ${ }^{8,43}$ Examining patterns of change among a population might explain disease trends due to changes in factors such as the annual frequencies of exposures, availability of screenings, use of new diagnostic technologies, and changes in disease coding. It is important to have data on the occurrence of a condition before and after the change factor being evaluated. In the case of cancer surveillance, there are some well-established sources of data (Surveillance, Epidemiology and End Results Registry; National Program of Cancer Registries).$^{44}$ It is also helpful if there is a clear change factor that has occurred as is seen in the similar slopes of reductions in lung cancer following reductions in smoking. ${ }^{8,45}$ Peaks in prostate cancer prevalence were correlated with the introduction of the first Prostate-specific antigen (PSA) screening and when follow-up biopsies became more routine..$^{45}$

Modeling change is an integral part of cancer surveillance. ${ }^{8}$ There are several important lessons learned from this modeling that can be useful when examining changes in ASD prevalence. The basic steps of modeling change are:

- Characterizing changes in disease trends;

- Quantifying changes in the population that might explain trends;

- Identifying a mechanism for the effect of the population trend;

- Estimating the size of the effect on the risk of disease diagnosis; and

- Modeling or simulating experience among the population.

All of these steps are equally necessary and applicable in explaining changes in ASD prevalence. However, modeling techniques might be useful if the potential effects of a factor on prevalence are not known. The Cancer Intervention and Surveillance Modeling Network is working to develop techniques for modeling changes in cancer based on multiple factors. ${ }^{46}$ The work of this group might be helpful in understanding ASD prevalence changes.

Parkinson's disease is a relatively rare disorder with associated environmental and genetic risk factors that does not have a definitive diagnostic test or marker. ${ }^{8}$ As with ASDs, population-based surveillance is 
challenging and there have been changes in diagnostic criteria over time. ${ }^{47}$ Also similar to autism, there are questions about the higher prevalence in males and differences by race. ${ }^{48}$ Based on diagnosed cases, researchers have identified increased occurrence of Parkinson's disease among men and with increasing age, a pattern that has been seen in most populations worldwide..$^{47,48}$ However, at this point, there are few sources of data to examine population trends in Parkinson's disease. The California Parkinson's Disease Registry is a pilot effort to create a population-based database with active ascertainment and case validation, but it is a limited effort. ${ }^{49}$ Advocacy groups support a national surveillance system for Parkinson's disease, but this has yet to be realized. Researchers are also examining conditions with similar symptoms and/or risk factors to identify common biologic mechanisms. It may be useful to study prevalence changes in other disorders with symptoms that overlap with ASDs and among adults. ${ }^{8,50}$

Asthma is a highly prevalent chronic disease. Studies have shown persistent demographic differences in prevalence, as well as health care use. Asthma surveillance relies on several national datasets such as the National Health Interview Survey (NHIS) and the Behavioral Risk Factor Surveillance System (BRFSS) to determine prevalence and severity. ${ }^{51,52}$ While asthma prevalence has increased over time, actual asthma attack rates have been relatively stable. The reasons for overall prevalence increases are not known, but there are sociodemographic disparities in identification and service use. Changes in survey measurement have affected asthma estimates. There is a challenge in examining asthma in relation to environmental factors as data are not available to look at direct measures among individuals in the population over time, but different datasets could be linked to conduct ecologic analysis of asthma survey data based on residence and air quality, for example. ${ }^{8}$

There are many parallels between schizophrenia and ASDs in the attempts to estimate and understand variation in incidence. With respect to schizophrenia and related psychoses, two landmark World Health Organization (WHO) studies can be used to mark shifts in thinking about schizophrenia and understanding of occurrence. ${ }^{52}$ The International Pilot Study of Schizophrenia (IPSS), conducted in the 1960s, was designed to determine if schizophrenia was a culturally bound disorder and if it was a "real" disorder (some people hypothesized that schizophrenia was a social construct). ${ }^{53,54}$ The study used standardized criteria in a multinational study and many regions of the world were included. Researchers found schizophrenia in all settings. Second, the WHO "Ten Country Study" examined whether the incidence and course of schizophrenia varied across sociocultural settings. Based on misinterpretation of the results of schizophrenia 
studies, the prevailing summary of schizophrenia from 1980 to about 2005 was that there was a lifetime risk of schizophrenia of one percent, and that this figure remained constant over time and place. The current view on schizophrenia is different. It is now clear that the occurrence varies across populations and population subgroups, the clearest example being the very high rates among some immigrants who are ethnic minorities. ${ }^{8,54,55}$ The WHO studies were not designed to examine change over time. Although other studies have attempted to examine change over time (e.g., registry studies), the results have been inconsistent and the data weak (e.g., due to changes in diagnostic practices and systems). As a result, with the exception of one or two particular locations, it is unclear whether schizophrenia incidence has changed over time. ${ }^{8,54}$

There have been different waves of ideology that have influenced the way in which the data on incidence of ASDs have been interpreted, and in particular, on whether they demonstrate a "true" increase or not ("true" means over and above an increase due to changes in ascertainment and help-seeking). The schizophrenia example highlights the power of ideology in the interpretation of such data, and the need to be cognizant of it. In terms of ASDs, people tend to look at data as either, "yes, there has been an increase", or "no, there has not been an increase". The actual data are insufficient to draw a firm conclusion, but it is important to remain open to the possibility of a true increase. Commitment to either position is not necessary to use data to advocate for improved services. ${ }^{8}$

\section{Analytic Models}

Changes in identified ASD prevalence have been an observed phenomenon, yet the challenge lies in identifying the causes for the changes. Causal models, including sufficient-component cause models, can shed some light on the joint effects of multiple exposures. ${ }^{8}$ However, these models are unable to consider timing in a dynamic way or connections between individuals. A possible solution is to use complex systems models. ${ }^{56,57}$ Complex systems approaches are computational approaches that use computer-based algorithms to model dynamic interactions between individuals within and across levels of influence (such as social networks and neighborhoods) using simulated populations. Complex systems models can incorporate multilevel determinants of population health, connections between individuals, and patterns of feedback between exposures and outcomes over time. An analytic strategy for understanding multi-faceted health issues is "agent-based modeling", which can be used to predict changes among heterogeneous populations. The goal is to model outcomes 
observed by varying the variables that might contribute to an observed pattern, such as occurrence of health effects after a disaster. In the example of a disaster, there could be several different sets of variables that produce the same outcome. Complex systems models point to different possible explanations for observed phenomenon, a point that is likely relevant for understanding reasons for ASD trends. However, these analytic methods can be used in conjunction with empirical data to narrow down possible explanations and can play a central role in epidemiological analyses. ${ }^{8}$

A mathematical model has been applied to assess the impact of whether specific pre- and perinatal risk factors effect the recent ASD prevalence trends. ${ }^{58}$ According to the ADDM Network, there was a 57 percent increase in ASD prevalence from 2002 to $2006 .{ }^{16}$ The effect of a given risk factor on prevalence depends on the baseline prevalence of the risk factor (RFP), the change in RFP over time (cRFP), and the magnitude of the relative risk (RR). A number of previous studies have indicated that preterm birth and low birthweight are risk factors for ASDs. ${ }^{42}$ Other studies have implicated multiple birth, cesarean delivery, breech presentation, and assisted reproductive technology (ART) as possible risk factors. However, none has had sufficient values for RFP, cRFP, and RR to have accounted substantively to the recently observed ASD increase. While at an individual level, having one or more perinatal risk factors might convey a moderate or strong risk for ASD, these factors are unlikely to explain a large proportion of the population increase in ASD prevalence. A risk factor might be strongly associated with ASD and might be modifiable, but it might not have increased sufficiently in the population during the time frame of interest. Therefore, this risk factor might be related to an individual's risk for ASD but not related to the increase in population prevalence of ASD. The model demonstrated that for any factor to have made a noteworthy contribution to population changes in ASD prevalence during a short time period, three conditions must be met: the factor must be fairly prevalent in the population, must have increased substantially, and must be strongly associated with diagnosed ASD. The model is accurate for shorter time intervals such as a few years. As the time period gets longer, different analytic models might be needed.

\section{DISCUSSION}

Panel members offered a range of perspectives on whether it will ever be possible to understand the relative contributions of identification and risk in increasing ASD prevalence. ${ }^{8}$ Debates about reasons for increases in ASD 
prevalence often have been dichotomized into explanations related to factors such as better identification and others arguing that the increase implicates specific environmental factors. ${ }^{59}$ Although it is clear that some of the increase is related to identification factors, a true increase cannot be ruled out, and furthermore, is hard to determine. In order to evaluate ASD prevalence changes, researchers tend to rule out alternative explanations by examining parsimonious and easily observable factors that could explain a difference over time, such as changes in patterns of identification. A more complex challenge is to search for the many potential and unknown risk factors that might be contributing to increases in ASD prevalence. As more data are collected and analyzed and different hypotheses evaluated over time and across studies, such risk factors can be identified..$^{60}$ Despite many efforts, a single, simple explanation has not been found indicating that there are likely multiple, overlapping factors contributing to increases in ASD prevalence.

There was a general sense that it is possible to move forward and to be more specific in documenting potential risk factors that could account for ASD prevalence trends. Several challenges can be identified, such as insurmountable measurement error, overlap and confounding of multiple identification and risk factors, and poorly defined subtypes with limited information on biological underpinnings to explain phenotypes. It is unlikely that prevalence trend data will explain the etiology of a complex set of conditions, such as ASDs, but these data can identify clues for further mechanistic studies (e.g., increased risk by sex, geography, and birth characteristics) ${ }^{60}$ Our understanding of the potential causal mechanisms for ASDs makes it clear that autism is not caused solely by genetic factors. In general, rapid increases in a purely inherited genetic condition are unlikely. However, shorter-term changes can be seen through de novo mutations or epigenetic changes. ${ }^{5,6}$ There is sufficient evidence to motivate the pursuit of both complex biologic and environmental factors in the etiologies of ASDs. ${ }^{61,62}$ Research using other methods that directly examine risk factors and potential causes of autism, rather than prevalence studies, will likely be most fruitful in clarifying the reasons for the increases in measured prevalence. In addition, we need more clarity on the variable expression of autism across the lifespan, and whether there is any association between trends for autism and other conditions. Perhaps the greatest value of prevalence data is that this information can lead to a focus on services and provide information regarding how to improve identification and access to such services.

There was agreement that the ASD prevalence is a huge public health problem and that many individuals and families are affected globally. At the community level, prevalence data have informed stakeholders about needed improvements in identifying people with an ASD and helped direct 
research that may ultimately lead to information about etiology. Similarly, the resulting increase in ASD awareness and knowledge among parents, caregivers, and communities has increased the quality of social and behavioral descriptions by clinicians and service providers when a child has been referred for an evaluation. This has resulted in parents and professionals being more equipped to discuss concerns. Individuals with an ASD have also benefitted from ASD prevalence data with increased ASD awareness related to positive community connections and increased information has allowed them to help themselves and others understand their experience. Prevalence estimates also have informed policy efforts to create an infrastructure to support children with an ASD (e.g., child care, intervention, education, transition services); understand and address lifespan issues (e.g, early identification, housing training, employment, health and wellness); drive public policy and programs (e.g., insurance coverage and health care legislation); and support the need for service deployment, systems planning, and additional research funding.

\section{WHAT CAN BE DONE?}

Throughout the workshop, ideas for building on existing infrastructure and for developing new initiatives to better understand ASD trends were discussed. ${ }^{8}$ In particular, efforts are needed to improve the specificity in quantifying and qualifying the multiple factors that might be influencing trends in ASD prevalence. These suggestions for improving our understanding of ASD trends are included below:

1. Collaboration: Collaboration among professionals and stakeholders is important, and the following points may assist collaborative efforts among those interested in understanding ASDs and supporting the ASD community through science:

- Continue efforts to develop and enhance communication among families, individuals affected, researchers, service providers, advocates, and government entities about ASD prevalence, research, and service needs.

- Seek public-private partnerships to support data collection, analyses, and usage.

- Seek input from and collaboration with those in other fields, such as cancer epidemiology, to identify and utilize methodologies for evaluating changes in the prevalence of complex conditions.

- Collaborate with other data systems to improve access to populationlevel environmental data. 
2. Analytic Activities: Improve utilization of existing data to understand ASD prevalence trends:

- Provide funding opportunities to encourage analyses and dissemination of findings from existing datasets.

- Link existing datasets identifying children with ASDs to other health, service, and research databases.

- Conduct analyses that will help explain variations in ASD prevalence across subgroups (e.g., race and ethnicity, sex, diagnostic subtype, and geographic groups) and if variation persists over time.

- Use complex modeling and multifactorial analyses to better understand variation in ASD prevalence such as by possible etiologic subgroups (e.g., specific genetic conditions and family history), geography, and sex, and by potentially harmful exposures among cohorts.

- Conduct simulation studies to predict the anticipated course of ASD prevalence.

3. Data Enhancements to Inform Practice: Data on the prevalence and characteristics of people with an ASD should be used to better inform service and support efforts:

- In addition to prevalence estimates, provide more in-depth information on population characteristics of people with an ASD (such as functional level and impact of functional limitations, subtype, developmental characteristics, and associated conditions) to improve program planning and support needs.

- Examine data to better understand lags and disparities in ASD identification to, in turn, inform screening, identification, and program planning.

- Conduct analyses to provide better estimates of current and future needs of adults with an ASD.

4. Additional Studies: Beyond enhancements to existing data systems and uses, new types of data collection and studies are needed, including:

- Expand ASD prevalence efforts to include very young children and adults.

- Examine prevalence over time among older children by following up with those identified in previous studies.

- Conduct additional validation studies at various ADDM Network sites and use the results to enhance estimates of ASD prevalence.

- Conduct further studies to better understand who is identified and who is not identified in national parent report surveys and in servicebased data such as special education child counts. 
- Develop ways of better capturing the heterogeneity of ASD phenotypes including the complexity of core and associated features that may present in different combinations for people with an ASD.

- Improve tools for culturally sensitive screening and case confirmation among large populations.

- Identify ways to measure and monitor the traits associated with ASDs among the general population to reflect various degrees (dimensional) rather than categorical (having an ASD or not having an ASD) case vs. not case) levels. This includes characterizing how these traits overlap with other conditions and typical development.

- Conduct prospective cohort, cross-sectional, and longitudinal studies following cohorts over time. This could include examining trends in characteristics of the population, such as ASDs among specific subgroups (based on, for example, race and ethnicity, immigrant status, and SES), age of identification, diagnoses, comorbidities, services use, and family characteristics.

- Monitor trends in ASD prevalence prospectively to rule out identification factors by consistently conducting developmental and ASD screening at a given age with diagnostic follow-up and documentation of each step and outcome.

- Conduct prospective studies that examine biology, phenotype, identification patterns, and service needs and use of people with an ASD.

- Expand international prevalence work to examine variability in occurrence that may shed light on identification and risk factors for ASDs.

- Examine trends in other behaviorally defined conditions (e.g., ADHD, depression, and anxiety).

\section{SUMMARY}

The identified prevalence of ASD has increased significantly in a short time period across multiple studies. ASDs are conditions estimated to occur among about one percent or more of children from multiple studies. Prevalence studies provide descriptive data on the number of people with a condition in a defined population. These studies are not sufficient to identify what causes ASDs. However, prevalence studies can be used as tools to examine variation in occurrence of ASDs across place, groups, time, and exposures, which may provide clues about groups that are at increased risk for ASDs. Other study designs would be necessary to fully investigate the reasons behind observed variation in ASD prevalence. At this point, it is 
clear that identification factors have had an impact on the identified prevalence, but no single factor explains the changes identified in ASD prevalence over time, and much needs to be done to understand the relative contribution of the multiple factors involved. Additionally, there are likely several forms of ASDs with multiple causes that are currently poorly understood. It was noted that sufficient evidence exists that biologic and environmental factors, alone and in combination need to be considered as causes of ASDs. By better understanding what causes ASDs, we may be able to understand the increases in measured prevalence.

Prevalence estimates have fueled action by advocacy groups and policy makers. However, individuals, families, and communities continue to have to address unmet needs across the lifespan of people with ASDs. ASDs are conditions that affect more individuals than previously thought and concerted efforts are needed to address the many associated needs of individuals, families, and communities in the context of a public health approach that includes improving preconception care for all, early medical and developmental screening and assessment, and needed support services across the lifespan.

\section{Acronyms List:}

ADDM $=$ CDC's Autism and Developmental Disabilities Monitoring Network $\mathrm{ADHD}=$ attention deficit/hyperactivity disorder

ASD $=$ autism spectrum disorder

CA DDS $=$ California Department of Developmental Services

IDEA = US Individuals with Disabilities Education Act

SES = socioeconomic status

About the Authors: Lisa A. Croen, PhD, is a Senior Research Scientist and the Director of the Kaiser Permanente ${ }^{\circledR}$ Autism Research Program. Currently, she is leading or collaborating on several federally funded autism studies, including the Study to Explore Early Development (SEED), the Early Autism Risk Longitudinal Investigation Study (EARLI), the Early Markers for Autism Study (EMA), the California Autism Twins Study (CATS), and the Mental Health Research Network Autism Registry project.

Geraldine Dawson, $\mathrm{PhD}$, is Chief Science Officer for Autism Speaks, Research Professor of Psychiatry at the University of North Carolina at Chapel Hill, Adjunct Professor of Psychiatry at Columbia University, and Professor Emeritus of Psychology at University of Washington. She is a licensed Clinical Psychologist who has published extensively on autism, focusing on early detection and intervention and early patterns of brain dysfunction.

Maureen Durkin, PhD, DrPH, is a Professor of Population Health Sciences and Pediatrics and Waisman Center Investigator at the University of Wisconsin-Madison and the Principal Investigator of the Wisconsin ADDM Network site. She is an epidemiologist specializing in population-based studies of the frequency, prevention, antecedents, and consequences of developmental disabilities. 
Catherine E. Rice, $\mathrm{PhD}$, is a Developmental Psychologist and Epidemiologist with CDC's National Center on Birth Defects and Developmental Disabilities, Developmental Disabilities Branch and has worked with people with an ASD through teaching, diagnostic assessment, intervention, training, and research. She was the Principal Investigator of the ADDM Network from 2001-2010. She currently works on public health programs related to autism with specific interests in early identification, diagnosis, and prevalence of autism.

Michael Rosanoff, MPH, is the Associate Director of Public Health Research and Scientific Review for Autism Speaks. He is a member of Autism Speaks etiology team and manages the organization's epidemiology and public health research grants. He is also the staff lead in overseeing the International Autism Epidemiology Network (IAEN) and is part of the development team for the Global Autism Public Health Initiative (GAPH).

Alison Singer, MBA, is Co-Founder and President of the Autism Science Foundation, a not-for-profit organization that funds autism research and serves to increase awareness of ASDs and the needs of individuals and families affected by autism. She has been very involved in advocacy for autism as the mother of a child with autism and legal guardian of her adult brother with autism. She spent 14 years at CNBC and $\mathrm{NBC}$ in a variety of positions, including vice president of programming in NBC's cable and business development division and as a producer. Ms. Singer has served on several research, advocacy, and government advisory boards for autism.

Marshalyn Yeargin-Allsopp, MD, is a Medical Epidemiologist and Branch Chief with the CDC's National Center on Birth Defects and Developmental Disabilities, Developmental Disabilities Branch. She designed and implemented the first U.S. population-based study of developmental disabilities in school-age children in an urban area, which has served as the basis for the ADDM Network and the Centers for Autism and Developmental Disabilities Research and Epidemiology (CADDRE) She has presented internationally and published extensively on the epidemiology of developmental disabilities, including autism and cerebral palsy.

Acknowledgements: Workshop on U.S. Data to Evaluate Changes in the Prevalence of the Autism Spectrum Disorders, Atlanta, Georgia, USA, February 1, 2011. Sponsored by the National Center on Birth Defects and Developmental Disabilities (NCBDDD), Centers for Disease Control and Prevention (CDC) and Autism Speaks. Workshop panelists included: Amanda V. Bakian*, MS, PhD, University of Utah; Thaer Baroud, BSN, MA, MHSA, Arkansas Center for Health Statistics; Peter Bearman, PhD, Columbia University; Peter Bell, MBA, Autism Speaks; Mark Blaxill, MBA, SafeMinds; Coleen A. Boyle, PhD, MSHyg, Centers for Disease Control and Prevention (CDC); Jane Charles, MD, Medical University of South Carolina; Prisca Chen Marvin, JD, parent of a child with autism; John N. Constantino, MD, Washington University in St. Louis; Adolfo Correa, MD, MPH, PhD, CDC; Krista S. Crider, MA, $\mathrm{PhD}, \mathrm{CDC}$; Lisa A. Croen, PhD, Kaiser Permanente; Christopher Cunniff, MD, FACMG, FAAP, University of Arizona, Tucson; Julie Daniels*, PhD, University of North Carolina at Chapel Hill; Geraldine Dawson*, PhD, Autism Speaks, University of North Carolina at Chapel Hill; Owen Devine, PhD, CDC; Wolf F. Dunaway, selfadvocate; Maureen Durkin, PhD, DrPH, University of Wisconsin-Madison; Ruth 
Etzioni, PhD, Fred Hutchinson Cancer Research Center; Sandro Galea, MD, MPH, DrPH, Columbia University; Roy Richard Grinker, PhD, George Washington University; Irva Hertz-Picciotto, PhD, University of California, Davis; Young Shin Kim, MD, MPH, PhD, Yale University; Michael King MSW, PhD, CDC; Russell S. Kirby, PhD, MS, FACE, University of South Florida; Michael D. Kogan, PhD, US Health Resources and Services Administration's Maternal and Child Health Bureau; Cindy Lawler, PhD, US National Institute for Environmental Health Sciences; Li-Ching Lee, PhD, ScM, Johns Hopkins University; Eric London, MD, Center for Discovery in Harris, New York; Maya Lopez, MD, University of Arkansas Medical Sciences; Matthew Maenner, $\mathrm{PhD}$, University of Wisconsin; Gerald McGwin, PhD, University of Alabama at Birmingham; William M. McMahon, MD, University of Utah; Kathleen Ries Merikangas, PhD, National Institute of Mental Health (NIMH); Lisa Miller, MD, MSPH, Colorado Department of Public Health and Environment; Beverly Mulvihill MEd, PhD, University of Alabama at Birmingham; Craig Newschaffer, PhD, Drexel University; Joyce S. Nicholas PhD, Medical University of South Carolina; Lars Perner, PhD, University of Southern California; Sydney Pettygrove, PhD, University of Arizona, Tucson; Catherine E. Rice*, PhD, CDC; John Elder Robison, self-advocate; Michael Rosanoff*, MPH, Autism Speaks; Diana E. Schendel, PhD, CDC; Laura A. Schieve, PhD, CDC; Stuart K. Shapira, MD, PhD, CDC; Paul T. Shattuck, PhD, Washington University in St. Louis; Ezra Susser, MD, DrPH, Columbia University; Alison Singer, MBA, Autism Science Foundation; Caroline M. Tanner, MD, PhD, FAAN, Parkinson's Institute in Sunnyvale, California; Kim Van Naarden Braun, PhD, CDC; Susanna Visser, MS, CDC; Gayle Windham, $\mathrm{PhD}$, California Department of Public Health; Martha S. Wingate*, DrPH, University of Alabama at Birmingham; Marshalyn Yeargin-Allsopp*, MD, CDC; Paula Yoon, MPH, ScD, CDC; Matthew Zack, MD, CDC; Walter Zahorodny, PhD, New Jersey Medical School; Judith Pinborough Zimmerman, PhD, CCC, University of Utah.

* Planning Committee including: Carrie Arneson, MSc, University of Wisconsin-Madison; Thomas A. Bartenfeld, PhD, CDC; Keydra Phillips, MSc, CDC; Anita Washington, MPH, Research Triangle Institute (RTI).

Conflicts of Interest: None declared.

\section{REFERENCES}

1. American Psychiatric Association. Diagnostic and Statistical Manual of Mental Disorders, 4th Edition, Text Revision (DSM-IVTR). Washington, DC: American Psychiatric Publishing; 2000.

2. Volkmar FR, Paul R, Klin A, Cohen D (editors). Handbook of Autism and Pervasive Developmental Disorders, Vol. 1: Diagnosis, Development, Neurobiology, and Behavior (3rd ed.). Hoboken NJ: John Wiley \& Sons Inc; 2005.

3. Levy S, Giarelli E, Lee L, Schieve L, Kirby R, et al. Autism spectrum disorders and co-occurring developmental, psychiatric, and medical conditions among children in multiple populations of the United States. J Dev Behav Pediatr.2010;31:267-75. 
4. Centers for Disease Control and Prevention. Prevalence of autism spectrum disorders - autism and developmental disabilities monitoring network, 14 sites, United States, 2008. MMWR Surveill Summ. 2012;61:1-19.

5. Abrahams B, Geschwind D. Advances in autism genetics: on the threshold of a new neurobiology. Nat Rev Genet. 2008;9:341-55.

6. Lichtenstein P, Carlström E, Råstam M, Gillberg C, Anckarsäter H. The genetics of autism spectrum disorders and related neuropsychiatric disorders in childhood. Am J Psychiatry. 2010;167:1357-63.

7. Daniels JL. Autism and the environment. Environ Health Perspect. 2006;114: A396.

8. Workshop on US data to evaluate changes in the prevalence of autism spectrum disorders. February 1, 2011, Atlanta, Georgia, U.S. Available from URL: http://www.cdc.gov/NCBDDD/autism/documents/EvaluatingChanges_ WorkshopSummary.pdf (Accessed 12 July 2012).

9. Newschaffer C, Croen L, Daniels J, Giarelli E, Grether J, et. al. The epidemiology of the autism spectrum disorders. Annu Rev Public Health. 2007; 28:235-58.

10. Rice C. Time trends in diagnosis. In: Volkmar F (Editor). Encyclopedia of Autism Spectrum Disorders. Springer; In press.

11. Fombonne E. Epidemiology of pervasive developmental disorders. Pediatr Res. 2009;65:591-8.

12. Cavagnaro, A. Autistic spectrum disorders changes in the California caseload an update: June 1987-June 2007. California Department of Developmental Services. 2009; 19:536-51.

13. Newschaffer C, Falb M, Gurney J. National autism prevalence trends from United States special education data. Pediatrics. 2005; 115: 277-82.

14. Bertrand J, Mars A, Boyle C, Bove F, Yeargin-Allsopp M, Decoufle P. Prevalence of autism in a United States population: the Brick Township, New Jersey, investigation. Pediatrics. 2001;108:1155-61.

15. Yeargin-Allsopp M, Rice C, Karapurkar T, Doernberg N, Boyle C, Murphy C. Prevalence of autism in a US metropolitan area. JAMA 2003;289:49-55.

16. Centers for Disease Control and Prevention. Prevalence of autism spectrum disorders - autism and developmental disabilities monitoring network, united states, 2006. MMWR Surveill Summ. 2009;58:1-20.

17. Hertz-Picciotto I, Delwiche L. The rise in autism and the role of age at diagnosis. Epidemiology. 2009;20:84-90.

18. King M, Bearman P. Diagnostic change and the increased prevalence of autism. Int J Epidemiol. 2009;38:1224-34. (Commentaries by Charman, Formbonne, Hertz-Picciotto, Rutter, and response).

19. Baird G, Simonoff E, Pickles A, Chandler S, Loucas T, et al. Prevalence of disorders of the autism spectrum in a population cohort of children in South Thames: the special needs and autism project (SNAP). Lancet. 2006;368:210-5.

20. Baron-Cohen S, Scott F, Allison C, Williams J, Bolton P, et al. Prevalence of autism spectrum conditions: UK school-based population study. $\mathrm{Br} \mathrm{J}$ Psychiatry. 2009; 194:500-9. 
21. Brugha TS, McManus S, Bankart J, Scott F, Purdon S, et al. Epidemiology of autism spectrum disorders in adults in the community in England. Arch Gen Psychiatry. 2011;68:459-65.

22. Honda H, Shimizu Y, Rutter M. No effect of MMR withdrawal on the incidence of autism: a total population study. J Child Psychol Psychiatry. 2005; 46:572-9.

23. Kadesjö B, Gillberg C, Hagberg B. Brief report: autism and asperger syndrome in seven-year-old children: a total population study. J Autism Dev Disord. 1999;29:327-31.

24. Kogan M, Blumberg S, Schieve L, Boyle C, Perrin J, et al. Prevalence of parentreported diagnosis of autism spectrum disorder among children in the U.S., 2007. Pediatrics. 2009;124:1395-403.

25. Society for Research in Child Development (SRCD). Social policy report on the autism spectrum disorders. SRCD Social Policy Report. 2010:24(2).

26. Rutter M. Incidence of autism spectrum disorders: changes over time and their meaning. Acta Paediatr. 2005;94:2-15.

27. Individuals with Disabilities Education Act (IDEA) Data. Washington, DC: U.S. Department of Education, Office of Special Education Programs; 2009. Number of children served under IDEA by disability and age group through 2007. Available from URL: https://www.ideadata.org/PartBData.asp (Accessed 26 February 2013).

28. Shelton J, Tancredi D, Hertz-Picciotto I. Independent and dependent contributions of advanced maternal and paternal ages to autism risk. Autism Res. 2010;3:30-9.

29. Van Meter K, Christiansen L, Delwiche L, Azari R, Carpenter T, Hertz-Picciotto I Geographic distribution of autism in California: a retrospective birth cohort analysis. Autism Res. 2010;3:19-29.

30. Liu K, King M, Bearman P. Social influence and the autism epidemic. AJS. 2010;115:1387-434.

31. Cheslack-Postava K, Liu K, Bearman PS. Closely spaced pregnancies are associated with increased odds of autism in California sibling births. Pediatrics. 2011;127:246-53.

32. Fountain C, King MD, Bearman PS. Age of diagnosis for autism: individual and community factors across 10 birth cohorts. J Epidemiol Community Health. 2011;65:503-10.

33. Keyes KM, Susser E, Cheslack-Postava K, Fountain C, Liu K, Bearman PS. Cohort effects explain the increase in autism diagnosis among children born from 1992 to 2003 in California. Int J Epidemiol. 2012;41:495-503.

34. Kim YS, Leventhal B., Koh Y., Fombonne E, Laska E, et al. Prevalence of autism spectrum disorders in a total population sample. Am J Psychiatry. 2011;168:904-12.

35. Roelfsema MT, Hoekstra RA, Allison C, Wheelwright S, Brayne C, et al. Are autism spectrum conditions more prevalent in an information-technology region? A school-based study of three regions in the Netherlands. J Autism Dev Disord. 2012;42:734-9. 
36. Rice C, Nicholas J, Baio J, Pettygrove S, Lee L, et. al. Changes in autism spectrum disorder prevalence in 4 areas of the United States. Disabil Health J. 2010;3:186-201.

37. Durkin M, Maenner M, Newschaffer C, Lee L, Cunniff C, et al. Advanced parental age and the risk of autism spectrum disorder. Am J Epidemiol. 2008; $168: 1268-76$.

38. Van Naarden Braun K, Schieve L, Daniels J, Durkin M, Giarelli E, et al. Relationships between multiple births and autism spectrum disorders, cerebral palsy, and intellectual disabilities: autism and developmental disabilities monitoring (ADDM) network-2002 surveillance year. Autism Res. 2008;1:265-316.

39. Durkin M, Maenner M, Meaney F, Levy S, Diguiseppi C, et. al. Socioeconomic inequality in the prevalence of autism spectrum disorder: evidence from a U.S. cross-sectional study. PLoS One. 2010;5:e11551.

40. Kalkbrenner A, Daniels J, Chen J, Poole C, Emch M, Morrissey J. Perinatal exposure to hazardous air pollutants and autism spectrum disorders at age 8 . Epidemiology. 2010;21:631-41.

41. Shattuck PT, Durkin M, Maenner M, Newschaffer C, Mandell DS, et al. Timing of identification among children with an autism spectrum disorder: findings from a population-based surveillance study. J Am Acad Child Adolesc Psychiatry. 2009;48:474-83.

42. Kolevzon A, Gross R, Reichenberg A. Prenatal and perinatal risk factors for autism: a review and integration of findings. Arch Pediatr Adolesc Med. 2007; 161:326-33.

43. Ward EM, Thun MJ, Hannan LM, Jemal A. Interpreting cancer trends. Ann N Y Acad Sci. 2006;1076:29-53.

44. Wingo PA, Jamison PM, Hiatt RA, Weir HK, Gargiullo PM, et al. Building the infrastructure for nationwide cancer surveillance and control--a comparison between the National Program of Cancer Registries (NPCR) and the Surveillance, Epidemiology, and End Results (SEER) Program (United States). Cancer Causes Control. 2003;14:175-93.

45. Jemal A, Center MM, DeSantis C, Ward EM. Global patterns of cancer incidence and mortality rates and trends. Cancer Epidemiol Biomarkers Prev. 2010;19:1893-907.

46. Cancer Intervention and Surveillance Modeling Network (CISNET). National Cancer Institute, U.S. National Institutes of Health. Bethesda, MD. Available from URL: www.cisnet.cancer.gov (Accessed 26 February 2013).

47. Twelves D, Perkins KS, Counsell C. Systematic review of incidence studies of Parkinson's disease. Mov Disord. 2003;18:19-31.

48. Van Den Eeden S, Tanner C, Bernstein A, Fross R, Leimpeter A, et. al. Incidence of Parkinson's disease: variation by age, gender, and race/ethnicity. Am J Epidemiol. 2003;157:1015-22.

49. California Parkinson's Disease Registry (CPDR). Available from URL: www. capdregistry.org (Accessed 26 February 2013). 
50. Atladóttir H, Parner E, Schendel D, Dalsgaard S, Thomsen P, Thorsen P. Time trends in reported diagnoses of childhood neuropsychiatric disorders: a Danish cohort study. Arch Pediatr Adolesc Med. 2007;161:193-8.

51. Boyle CA, Boulet S, Schieve LA, Cohen RA, Blumberg SJ, et al. Trends in the prevalence of developmental disabilities in US children, 1997-2008. Pediatrics. 2011;127:1034-42.

52. Demir A, Celikel S, Karakaya G, Kalyonco A. Asthma and allergic diseases in school children from 1992 to 2007 with incidence data. J Asthma. 2010;47: 1128-35.

53. World Health Organization. Schizophrenia and public health. Division of Mental Health and Prevention of Substance Abuse, WHO: Geneva, Switzerland; 1998. Available from http://www.who.int/mental_health/media/ en/55.pdf (Accessed 26 February 2013).

54. McGrath JJ, Susser ES. New directions in the epidemiology of schizophrenia. Med J Aust. 2009;190:S7-9.

55. Myers NL. Update: schizophrenia across cultures. Curr Psychiatry Rep. 2011; 13:305-11.

56. Galea S, Hall C, Kaplan G. Social epidemiology and complex system dynamic modeling as applied to health behaviour and drug use research. Int J Drug Policy. 2009;20:209-16.

57. Galea S, Riddle M, Kaplan G. Casual thinking and complex system approaches in epidemiology. Int J Epidemiol. 2010;39:97-106.

58. Schieve LA, Rice C, Devine O, Maenner MJ, Lee LC, et al. Have secular changes in perinatal risk factors contributed to the recent autism prevalence increase? Development and application of a mathematical assessment model. Ann Epidemiol. 2011;21:930-45.

59. Weintraub K.The prevalence puzzle: autism counts. Nature. 2011;479:22-4.

60. Schwartz S, Susser E. Commentary: what can epidemiology accomplish? Int J Epidemiol. 2006;35:587-90; Discussion 593-6.

61. Institute of Medicine of the National Academies. Autism and the Environment: Challenges and Opportunities for Research. Workshop Proceedings. Washington, DC: The National Academies Press; 2007. Available from URL: http://books.nap.edu/openbook.php?record_id=11946 (Accessed 26 February 2013).

62. Rutter ML Progress in understanding autism: 2007-2010. J Autism Dev Disord. 2011;41:395-404. 